\title{
A Base Nacional Curricular Comum e a formação dos professores de arte
}

\author{
Rosa Iavelberg*
}

\begin{abstract}
Resumo
$\mathrm{O}$ presente artigo analisa a terceira versão do documento A Base Nacional Curricular Comum (BNCC), dedicando atenção especial à passagem das proposições dos Parâmetros Curriculares Nacionais (PCN) para o documento em questão. Nesse sentido, pretende-se constatar as continuidades e as descontinuidades existentes entre ambos, além disso, examina-se o texto da BNCC, visando refletir sobre suas potencialidades e seus limites como documento-referência e de adoção obrigatória na construção dos currículos e dos projetos políticos pedagógicos das escolas e redes. Abordaremos, nesse exercício, as possíveis barreiras e o diálogo entre a BNCC, a formação de professores e os contextos escolares.

Palavras-chave: BNCC; PCN; Currículo; Ensino Fundamental 1; Continuidades e Descontinuidades.
\end{abstract}

\section{National Curricular Common Base and Art teachers training}

\begin{abstract}
This article analyzes the third version of the National Curricular Common Base in relation to the National Curricular Parameters propositions to the BNCC, verifying continuities and discontinuities. To validate these ideas, we will analyze these documents and reflect upon them, comparing their different aspects. We will access the BNCC text to determine the possibilities and the limits of the document which aims to be the reference of compulsory adoption in the construction of the curricula and the pedagogical political projects of the schools and networks. Thus, we will discuss the possible barriers and the dialogue between BNCC, teachers training and school contexts.

Keywords: BNCC; PCN; Curriculum; Elementary Education; Continuities and Discontinuities.
\end{abstract}

A Base Nacional Comum Curricular (BNCC), em sua terceira versão, elaborada em 2017, propõe grande mudança nos currículos de Arte da Educação Básica. Assim, compreendemos ser necessário o exame dos limites e das possibilidades que a BNCC oferece ao trabalho nas escolas, em especial frente às orientações presentes anteriormente nos Parâmetros Curriculares Nacionais $(\mathrm{PCN})$ de Arte, editados em 1997. Diante da extensão desta investigação, concentraremos esforços na análise da terceira versão da $\mathrm{BNCC}$, disponível à época da escrita do presente artigo, no segmento do Ensino Fundamental $1\left(1 .^{\circ}\right.$ ao $5 .^{\circ}$ ano), sem remissão às versões anteriores da Base, isso porque não será nosso propósito compará-las. De antemão, sabemos que a quarta versão implicará na reestruturação dos currículos das escolas e dos projetos políticopedagógicos das mesmas. Os livros escritos para o Programa Nacional do Livro e Material Didático (PNLD) de 2019 foram realizados a partir da terceira versão, portanto, serão reformulados.

O eixo principal de nossa análise incidirá sobre as Artes Visuais. Trataremos das demais unidades temáticas, tais como, Dança, Música, Teatro e Artes Integradas, ao abordarmos aspectos gerais dos documentos. Teremos como objeto central de investigação o texto do componente Arte da BNCC (2017), do $1 .^{\circ}$ ao 5..$^{\circ}$ ano. Algumas vezes, cotejaremos as proposições desse documento com as dos PCN (1997) da área de Arte, do $1 .{ }^{\circ}$ ao $4 .^{\circ}$ ano (atual Fundamental 1), exceto à inclusão do $10^{\circ}$ ano na BNCC (pertencente, anteriormente, à Educação Infantil). Isso não interferirá em nosso estudo, pois trabalharemos com porcentagens relativas às questões quantitativas de cada documento - as demais análises não serão afetadas pela incorporação do atual $1 .^{\circ}$ ano.

Nesse exercício de reflexão, selecionaremos alguns aspectos dos textos para neles verificar o que foi preservado ou derivado dos PCN na BNCC, demarcando continuidades, e o que foi inovado e abandonado na Base em relação às concepções dos Parâmetros, indicando descontinuidades. Intencionamos tematizar a respeito das condições a serem enfrentadas na implantação da BNCC nas escolas e na formação dos professores, considerando que, no Ensino Fundamental 1, o professor regente, com formação em Pedagogia e sem licenciatura específica em uma das linguagens do componente Arte, ainda segue autorizado a ministrar aulas em todas elas. Não situamos artigos de periódicos ou livros que tratam da BNCC de Arte com remissão aos PCN na perspectiva que assumimos de examinar os textos dos documentos

*Endereço Eletrônico: rosaiave@usp.br 
cotejando-os. Não é nossa intenção, neste trabalho, apontar posicionamentos favoráveis e contrários a um ou ao outro documento, pois nos deslocaria do que aqui será possível investigar, contudo, consideramos que tal análise é de fundamental relevância.

\section{BNCC e PCN}

Na BNCC, do $1 .^{\circ}$ ao $5 .^{\circ}$ ano, a Arte é tratada como componente da área de Linguagens, ao lado de Educação Física e de Língua Portuguesa. Já nos PCN foi inserida como área de conhecimento em documento próprio e em igualdade com as demais áreas (Ciências, Educação Física, Geografia, História, Língua Portuguesa e Matemática) - existe, então, uma equivalência não observada na BNCC. Além disso, os documentos dos Temas Transversais - Pluralidade Cultural, Ética, Meio Ambiente, Orientação Sexual e Saúde - eram orientados a todas as áreas e, entre elas, à de Arte. As diferenças que acabamos de mencionar incidem sobre o número de páginas, ou seja, sobre o espaço ocupado pelas áreas e componentes nos dois documentos (Quadros I e II).

QUADRO I - Número de páginas nos documentos

\begin{tabular}{|l|l|}
\hline Número de páginas por área ou componente & \multicolumn{1}{c|}{ Número de páginas por área } \\
\hline BNCC $\left(1^{\circ}\right.$ ao $5^{\circ}$ ano do Ensino Fundamental 1$)$. & $\operatorname{PCN~}\left(1^{\circ}\right.$ ao $4^{\circ}$ ano do Ensino Fundamental $)$. \\
\hline Língua Portuguesa -49 & Arte -116 \\
\hline Matemática -35 & Língua Portuguesa -129 \\
\hline Geografia -22 & História -81 \\
\hline História -20 & Geografia -66 \\
\hline Ciências -18 & Educação Física -81 \\
\hline Educação Física -10 & Ciências Naturais -118 \\
\hline Arte -12 & Matemática -127 \\
\hline
\end{tabular}

Fonte: produção da própria autora.

QUADRO II - Porcentagem de páginas por área ou componente

\begin{tabular}{|l|l|}
\hline $\begin{array}{l}\text { BNCC Ensino Fundamental 1. } \\
\text { Total de páginas 173. }\end{array}$ & $\begin{array}{l}\text { PCN Ensino Fundamental (1. }{ }^{\mathbf{a} 0} \text { 4. }^{\mathbf{0}} \text { Ano) } \\
\text { Total de páginas 718. }\end{array}$ \\
\hline Língua Portuguesa (28\%) & Língua Portuguesa (18\%) \\
\hline Matemática (20\%) & Matemática (18\%) \\
\hline Geografia (13\%) & Geografia (9\%) \\
\hline História (12\%) & História (11\%) \\
\hline Ciências (10\%) & Ciências Naturais (17\%) \\
\hline Educação Física (10\%) & Educação Física (11\%) \\
\hline Arte (7\%) & Arte (16\%) \\
\hline
\end{tabular}

Fonte: produção da própria autora.

A contagem do número de páginas foi realizada, tomando-se o início da área ou do componente, sem os textos introdutórios, no caso dos PCN, garantindo equidade no cálculo entre os documentos. Incluíram-se as bibliografias dos Parâmetros, uma vez que essas integram o texto de cada área. Na BNCC, Língua Inglesa só é ensinada a partir do $6^{\circ}$ ano, portanto, não entrou nos quadros. Aqui se assinala que Língua Portuguesa, Artes e
Educação Física são componentes da área de Linguagens.

Ao observarmos os Quadros I e II, verificamos que na $\mathrm{BNCC}$ há maior diferença de extensão entre o componente Arte e os demais componentes e áreas, sendo Língua Portuguesa e Matemática os mais privilegiados. Há um equilíbrio maior entre a extensão do texto de Arte e os demais textos nos PCN em relação à BNCC. Essa 
descontinuidade denota uma desvalorização da Arte no currículo escolar e está em consonância com a exclusão do componente das avaliações das aprendizagens dos sistemas de ensino. Tais avaliações, acreditamos, revelam um caráter instrumental no texto da BNCC: a preocupação em atender ao mercado de trabalho e aos interesses do capital através de uma formação orientada a ele e à expansão de consumidores. Assim, é eclipsada a formação em Arte que promove um sujeito sensível e crítico, com possibilidade de participação artística e cultural na sociedade.

Carvalho (2017, p. 30) completa esse pensamento:

Portanto, a preocupação de pensar a experiência escolar a partir de suas finalidades práticas e de sua suposta relevância econômica tem posto em risco a possibilidade de se atribuir à formação educacional um significado político e existencial. Note-se que essa supremacia do caráter instrumental dos discursos educacionais não implica o desaparecimento de disciplinas e saberes tidos como integrantes de uma concepção humanista de formação, como a literatura, as artes ou a filosofia. Significa, antes, que mesmo esses saberes e disciplinas passam a ter outro papel: o de coadjuvantes na supremacia do instrumentalismo vinculado ao mercado e à sociedade de consumidores.

Outro aspecto que denota o rebaixamento do valor da Arte na Educação é o fato de que em todas as áreas e componentes da BNCC se definem itens, tais como, unidades temáticas, objetos de conhecimento $\mathrm{e}$ habilidades ano a ano ou congregando-os em dois grupos (do $1 .^{\circ}$ ao $3 .^{\circ}$ e do $3 .^{\circ}$ ao $5 .^{\circ}$ ano). Arte é o único componente sem nenhuma variação nesses itens do $1 .^{\circ}$ ao $5 .^{\circ}$ ano, contudo, isso não significa uma mudança de cultura em relação à avaliação seriada - o que poderia minimizar a tensão existente nas avaliações, abrindo oportunidade para um tempo expandido às aprendizagens ao longo do Fundamental I, apenas revela uma indefinição no que se refere aos conteúdos do ensino.

Em relação à estrutura dos documentos, na BNCC não se explicitam eixos de aprendizagem significativa como nos PCN: fazer, fruir e refletir sobre a produção social e histórica da Arte. Na BNCC, estão propostas seis dimensões do conhecimento: criação, crítica, estesia, expressão, fruição e reflexão. Essas seis dimensões não são eixos temáticos. Diferentemente dos PCN, são linhas maleáveis que se entrelaçam. Entretanto, entendemos que essas linhas podem ser colocadas paralelamente aos três eixos de aprendizagem significativa concebidos nos PCN, uma vez que são também articulados entre si. $\mathrm{O}$ alinhamento dos eixos (PCN) e das dimensões do conhecimento (BNCC) pode ser assim compreendido:

QUADRO III - Eixos de aprendizagem significativa e dimensões do conhecimento

\begin{tabular}{|l|l|l|l|}
\hline PCN & Fazer & Fruir & Refletir \\
\hline BNCC de aprendizagem significativa & Criação & Estesia & Crítica \\
Dimensões do conhecimento & Expressão & Fruição & Reflexão \\
\hline
\end{tabular}

Fonte: produção da própria autora.

Refletido sobre o Quadro III, verificamos que tanto os PCN como a BNCC, apesar de o fazerem de formas diversas, orientam-se por ações de aprendizagem relacionadas à Abordagem Triangular, defendida pela Profa. Ana Mae Barbosa, nos anos de 1980. Nessa proposta, apontou-se a necessidade de avançar em relação ao ensino modernista na Arte, instaurando uma articulação entre o fazer, a leitura da arte e sua contextualização (BARBOSA, 2014).
Outra terminologia usada na BNCC é objeto de conhecimento, aludindo às largas zonas de inclusão de habilidades que levam às competências. Tais zonas, relacionadas ao mundo da arte, se diferenciam muito pouco entre as unidades temáticas - Artes Visuais, Dança, Música, Teatro e Artes Integradas -, sendo que esta última não compõe o PCN; ela refere-se às linguagens da arte e às relações entre arte e tecnologia, como veremos adiante. 
QUADRO IV - Objetos de conhecimento em relação às unidades temáticas

\begin{tabular}{|c|c|}
\hline $\begin{array}{l}\text { Objetos de conhecimento } \\
1 .^{\circ} \text { ao 5. } .^{\circ} \text { ano. }\end{array}$ & Unidades temáticas. \\
\hline Contextos e práticas. & Artes Visuais; Dança; Música; Teatro. \\
\hline Elementos da linguagem. & Artes Visuais; Dança; Música; Teatro. \\
\hline Matrizes estéticas e culturais. & Artes Visuais; Artes Integradas. \\
\hline Materialidades. & Artes Visuais; Música. \\
\hline Sistemas da linguagem. & Artes Visuais. \\
\hline Processos de criação. & Artes Visuais; Dança; Música; Teatro e Artes Integradas. \\
\hline Notação e registro musical. & Música. \\
\hline Patrimônio cultural. & Artes Integradas. \\
\hline Arte e tecnologia. & Artes Integradas. \\
\hline
\end{tabular}

Fonte: produção da própria autora.

No lugar do termo objeto de conhecimento, e com outra concepção, nos PCN, foram delineados conteúdos, distribuídos nos três eixos de aprendizagem significativa: fazer, fruir e refletir. A distribuição dos conteúdos orientou-se por seus diferentes tipos, tais como: fatos, conceitos, princípios, procedimentos, valores e atitudes. Essa tipologia dizia respeito aos diversos modos da aprendizagem (ZABALA, 1998). Essa diferenciação na maneira de aprender foi explicitada nos documentos, pois, apesar do entrelaçamento entre as várias categorias de conteúdo, o que estava em pauta nos PCN era a necessidade de orientações didáticas distintas que dependiam da especificidade do que seria aprendido. Já na BNCC, os objetos de conhecimento se associam às habilidades, que, por sua vez, relacionam-se às competências específicas do componente Arte, às da área de Linguagens (na qual, a Arte está alocada) e, ainda, às competências gerais do Ensino Fundamental.

\section{Competências, habilidades e conteúdos}

Na BNCC, não é explícito que a aprendizagem promove desenvolvimento e que esse não é ensinável, isto porque se trata de processo endógeno proporcionado pelas aprendizagens das habilidades que serão avaliadas. As competências como o desenvolvimento - não podem ser ensinadas, pois se constroem a partir da aprendizagem das habilidades. Segundo Zabala e Arnaud (2010), a ideia de competência nasce no mundo do trabalho e estende-se à Educação em contraposição ao ensino tradicional baseado na memorização dos conteúdos. Para eles, competência é a capacidade de mobilizar diferentes tipos dos conteúdos: conceitos, procedimentos e atitudes de modo integrado, por intermédio das habilidades. Sendo assim, acreditamos que a aprendizagem das habilidades constrói as competências necessárias à formação dos estudantes.

Os autores supracitados afirmam ser muito complicado julgar o avanço das competências, uma vez que isso demandaria situações reais de verificação dos diferentes âmbitos de cada uma delas. Na prática, aos professores cabem avaliar as habilidades e indicar as possíveis competências a elas relacionadas por meio de registros, observações e análise dos trabalhos desenvolvidos nas diferentes dimensões do conhecimento, propostas na BNCC o que devemos mencionar é tarefa bastante complexa.

Some-se ainda que, nas orientações da BNCC, é frágil a definição de indicadores e balizas teóricas para a seleção dos conteúdos, tornando difícil aos professores relacioná-los às habilidades que levariam às competências. A não menção de tais indicadores está em contradição com o documento, que tem caráter obrigatório e de base comum para todo o país. Além disso, a parte diversificada do currículo, a ser planejada pelas equipes escolares em consideração às especificidades dos contextos nos quais as escolas se inserem, terá que dialogar com a proposição metodológica e com os conteúdos do segmento obrigatório.

Nas Diretrizes Curriculares Nacionais da Educação Básica (DCNEB), lê-se que:

A articulação entre a base nacional comum e a parte diversificada do currículo do Ensino Fundamental possibilita a sintonia dos interesses mais amplos de formação básica do cidadão com a realidade local, as necessidades dos alunos, as 
características regionais da sociedade, da cultura e da economia e perpassa todo o currículo (BRASIL, 2013, p. 113).

Cabe ressaltar que os demais componentes e áreas definem com clareza os conteúdos que estão em jogo no exercício das habilidades, como veremos adiante.

A título de exemplo de conteúdo associado ao eixo de aprendizagem significativa do fazer, nos $\mathrm{PCN}$, encontramos o texto abaixo descrito:

Fazer ou Expressão e Comunicação na Prática dos Alunos em Artes Visuais

Reconhecimento e utilização dos elementos da linguagem visual representando, expressando e comunicando por imagens: desenho, pintura, gravura, modelagem, escultura, colagem, construção, fotografia, cinema, vídeo, televisão, informática, eletrografia. (BRASIL, 1997, p. 62, grifo nosso).

Tomando o objeto de conhecimento Materialidades, da BNCC e a habilidade a ele correlata ao conteúdo acima descrito, vemos, na unidade temática Artes Visuais, a habilidade EFAR1504, sigla que significa Ensino Fundamental de Arte do $1 .^{\circ}$ ao $5 .^{\circ}$ ano, habilidade 04:

\section{Objeto de conhecimento: Materialidades \\ Experimentar diferentes formas de expressão artística (desenho, pintura, colagem, quadrinhos, dobradura, escultura, modelagem, instalação, vídeo, fotografia, etc.), fazendo uso sustentável de materiais, instrumentos, recursos e técnicas convencionais e não convencionais (BRASIL, 2017a, p. 159, grifo nosso).}

Destacamos, nas duas citações acima, o que foi inovado no texto da BNCC e o que não foi citado e estava arrolado nos PCN, ou seja, itens abandonados (gravura, televisão, informática, eletrografia), que ao lado dos inovados (quadrinhos, dobradura, instalação, uso sustentável de materiais, instrumentos, recursos e técnicas convencionais e não convencionais) apontam descontinuidades. As continuidades residem nos itens coincidentes e nos derivados dos PCN que se expandem pela inclusão do etc na BNCC.

A título de exemplo de conteúdo associado ao eixo de aprendizagem significativa da fruição, existia nos PCN o texto abaixo descrito:

\footnotetext{
Fruição ou as Artes Visuais como Objeto de Apreciação Significativa
}

Reconhecimento, experimentação e leitura dos elementos básicos da linguagem visual, em suas articulações nas imagens apresentadas nas diferentes culturas (relações entre ponto, linha, plano, cor, textura, forma, volume, luz, ritmo, movimento, equilíbrio) (BRASIL, 1997, p. 64, grifo nosso).

Analisando o objeto de conhecimento Elementos da Linguagem da unidade temática Artes Visuais da BNCC, encontramos a habilidade EF15AR02, correlata aos conteúdos acima citados.

Objeto de conhecimento: Elementos da
Linguagem
Explorar e reconhecer elementos constitutivos
das artes visuais (ponto, linha, plano, cor,
espaço, textura, forma, volume, luz, ritmo,
movimento, equilíbrio) (BRASIL, 2017a, p. 159,
grifo nosso).

Aqui os itens em itálico referentes à $\mathrm{BNCC}$ coincidem com os itálicos dos $\mathrm{PCN}$, indicando continuidade; apenas o item espaço foi acrescentado como inovação apontando descontinuidade.

Verificamos que, na análise dos dois documentos em questão, focalizando as Artes Visuais, nos exemplos, acima citados e, nos demais casos (que não serão aqui arrolados), quando relacionamos um conteúdo dos PCN a uma habilidade da $\mathrm{BNCC}$, os conteúdos redigidos nos PCN tornaram-se habilidades na BNCC, demarcando, nessa passagem, tanto continuidades como descontinuidades. Em outras palavras, nos casos que aqui analisamos, constatamos que a transição de conteúdo à habilidade deu-se a partir da mudança do substantivo para verbo. Por exemplo, reconhecimento, que se refere a conteúdo no primeiro documento, na BNCC, passa a ser reconhecer no item habilidade.

Segundo Ferraz e Fusari (2009, p. 146), os conteúdos escolares em Arte:

São os assuntos substantivos em arte a serem trabalhados nos cursos. São aspectos essenciais selecionados pelos professores dentre os conhecimentos artísticos e estéticos produzidos historicamente e em produção pela humanidade nas diversas modalidades artísticas (música, artes visuais, teatro, dança, artes audiovisuais, entre outras), referem-se ao "o que" deve ser objeto de estudo no fazer artístico pessoal (a concretizar-se em produtos artísticos) e nas análises sobre artistas, obras de arte, modos de comunicação, públicos e suas histórias. Articulam-se aos objetos e finalidades 
educacionais escolares propostos em arte e demais componentes curriculares. A relevância e sentido cultural dos conteúdos selecionados devem ser objeto de avaliação.

Compreendemos que uma habilidade não pode ser aprendida sem que se especifique cada conteúdo a ela relacionado, pois para que as habilidades sejam postas em ação é necessária mobilização de um conjunto específico, não genérico, dos conteúdos a serem aprendidos. Tomemos como exemplo uma habilidade classificada na BNCC, como EFAR1503 (BRASIL, 2017a, p. 159) - a terceira entre as habilidades sequenciadas na unidade temática Artes Visuais -, que tem a ela associado o objeto de conhecimento Matrizes estéticas e culturais (Idem, p. 158). À habilidade em questão está correlacionado o texto: "Reconhecer e analisar a influência de distintas matrizes estéticas e culturais das artes visuais nas manifestações artísticas das culturas locais, regionais e nacionais" (Idem, p. 159).

Desta forma, para que esta habilidade seja exercida pelo aluno, são necessários conteúdos dessas diferentes matrizes estéticas e culturais, sejam locais, regionais ou nacionais.

Os demais componentes e áreas da BNCC definem com exatidão os conteúdos que promovem o exercício e a aprendizagem das habilidades. Em Matemática, temos como exemplo a $14 .^{a}$ habilidade do $4 .^{\circ}$ ano EF04LP15, vinculada ao objeto de conhecimento Propriedades da igualdade. A descrição da referida habilidade já contempla os conteúdos a ela associados e está assim enunciada:

Reconhecer e mostrar, por meio de exemplos, que uma igualdade não se altera quando se adiciona ou se subtrai um mesmo número a seus dois termos (BRASIL, 2017a, p.247).

Destacamos ainda a $8 .^{\mathrm{a}}$ habilidade do $3 .^{\circ}$ ano de Geografia, EF03GE08, vinculada ao objeto de conhecimento Produção, circulação e consumo e à unidade temática Natureza, ambientes e qualidade de vida. A descrição da referida habilidade, contempla, como a que acabamos de analisar, conteúdos a ela relacionados e está assim enunciada:

Relacionar a produção de lixo doméstico ou da escola aos problemas causados pelo consumo excessivo e construir propostas para o consumo consciente, considerando a ampliação de hábitos, de redução, reuso e reciclagem/descarte de materiais consumidos em casa, na escola e/ou no entorno. (BRASIL, 2017a, p. 327).

Nos dois casos acima, como nos demais de outras áreas e componentes, que não serão aqui arrolados, repetem-se a definição clara dos conteúdos a serem trabalhados para a aprendizagem de determinada habilidade e o ano no qual o conteúdo entrará no planejamento das aulas. Para demonstrar que o mesmo não ocorre em Arte, trazemos o exemplo a seguir: a $6 .^{\mathrm{a}}$ habilidade EFAR15906 do $1 .^{\circ}$ ao $5 .^{\circ}$ ano está vinculada ao objeto de conhecimento Processos de criação e à unidade temática Artes Visuais e foi assim redigida: Dialogar sobre a sua criação e as dos colegas, para alcançar sentidos plurais (BRASIL, 2017a, p. 159). Tal habilidade para ser aprendida requer, no mínimo, conteúdos procedimentais envolvidos nos modos do fazer artístico, para que se alcance os sentidos plurais enunciados de forma vaga e totalmente aberta. Não há no texto desta habilidade quais conteúdos poderiam ser observados ou indicações sobre possíveis formas de aproximação aos trabalhos uns dos outros; tampouco especificação sobre quais dimensões do conhecimento a habilidade está incluída para a aprendizagem do processo de criação.

Durante os atos de criação ou de reflexão compartilhada, ocorrem aprendizagens colaborativas entre os protagonistas, envolvendo os conteúdos específicos de diferentes ordens: da ação, da cognição, do âmbito da sensibilidade, entre outras, para que a criança expanda seu repertório em contato com a pluralidade de sentidos criados pelos colegas, seria necessário circunscrever aquilo que pode ser observado, como cores, gestos, seleção de meios e suportes, temas ou ações que foram desenvolvidas pelos pares situando os procedimentos utilizados, etc.

Assim sendo, a ordenação de conteúdos ligados às habilidades cuja aprendizagem é obrigatória, no caso de Arte, dependerá do empenho, da definição e do conhecimento dos professores. É esperado, se nos orientamos pelas competências e habilidades vinculadas ao componente Arte da BNCC, que a escrita curricular, tanto da parte obrigatória, como a da diversificada, seja elaborada a partir da seleção de conteúdos com significado social e ético, em uma perspectiva democrática, sem preconceitos e inclusiva em relação à diversidade da arte brasileira, das culturas regionais e da produção artística produzida por diferentes povos, tempos e lugares, guardando 
respeito às culturas que os alunos trazem consigo.

Em vista do que discorremos e considerando o modo como foram estruturadas as habilidades do componente Arte na BNCC, ficará a cargo das equipes escolares a seleção dos conteúdos. Sabe-se que, no segmento do Ensino Fundamental I, a maioria das escolas apresenta: número insuficiente de professores licenciados nas linguagens específicas; concursos polivalentes de ingresso na carreira docente; pouca carga didática reservada ao componente; baixa diversidade de materiais e, inadequação de espaço físico nas escolas para as aulas. Nesse contexto, tais fatores podem esvaziar a escrita curricular e o planejamento das aulas de conteúdos relevantes à formação dos alunos em Arte.

Acrescente-se a essas questões o fato dos objetos de conhecimento praticamente serem os mesmos do $1 .^{\circ}$ ao $5 .^{\circ}$ e do $6 .^{\circ}$ ao $9 .^{\circ}$ anos, com exceção feita à retirada de Matrizes estéticas $e$ culturais da unidade temática Artes Visuais (BRASIL, 2017a, p. 164) e à inclusão de Contextos e Práticas, na unidade temática Artes Integradas (Idem, p. 168). O que se fez, nos parece, foi tentar tornar mais complexas as mesmas habilidades no segundo período, ao invés de expandir as oportunidades de aprender outras ligadas a conteúdos distintos.

\section{Artes Integradas}

A unidade temática Artes Integradas, criada na BNCC e inexistente nos PCN, tem como objetivo integrar as demais (Artes Visuais, Dança, Música e Teatro) e as tecnologias da informação e da comunicação. Isso poderia ser compreendido como atualização diante da produção contemporânea de arte, uma vez que existem criações artísticas que integram as artes e as tecnologias, entretanto, as Artes Integradas podem ser a porta de entrada para a polivalência, tal preocupação com a interpretação do documento da BNCC já estava presente na equipe de elaboradores dos PCN.

De maneira geral, entre os anos 70 e 80 , os antigos professores de Artes Plásticas, Desenho, Música, Artes Industriais, Artes Cênicas e os recém-formados em Educação Artística viram-se responsabilizados por educar os alunos (em escolas de ensino médio) em todas as linguagens artísticas, configurando-se a formação do professor polivalente em Arte. Com isso, inúmeros professores deixaram as suas áreas específicas de formação e estudos, tentando assimilar superficialmente as demais, na ilusão de que as dominariam em seu conjunto. A tendência passou a ser a diminuição qualitativa dos saberes referentes às especificidades de cada uma das formas de arte e, no lugar destas, desenvolveu-se a crença de que bastavam propostas de atividades expressivas espontâneas para que os alunos conhecessem muito bem música, artes plásticas, cênicas, dança, etc (BRASIL, 1997, p. 24).

No documento da BNCC, o texto sobre Artes Integradas não explicita o problema da polivalência.

$\mathrm{Na}$ BNCC de Arte, cada uma das quatro linguagens do componente curricular - Artes Visuais, Dança, Música e Teatro - constitui uma unidade temática que reúne objetos de conhecimento e habilidades articulados às seis dimensões apresentadas anteriormente. Além dessas, uma última unidade temática, Artes Integradas, explora relações e articulações entre as diferentes linguagens e suas práticas, inclusive aquelas possibilitadas pelo uso das novas tecnologias de informação e comunicação (BRASIL, 2017a, p.155).

Em relação às demais áreas de conhecimento e componentes da BNCC, a não definição de conteúdo em Arte poderia representar uma abertura favorável à autonomia dos professores e gestores na seleção do o que ensinar ao definir os conteúdos. Porém, no edital do Programa Nacional do Livro e do Material Didático para 2019, nas orientações para a escrita do Manual do Professor Impresso, pede-se aos autores: “(...) explicitar a correspondência do conteúdo, com os objetos e conhecimento e habilidades (...)" (BRASIL, 2017b, p.36). Essa exigência de definição do conteúdo, que estaria em correspondência com os objetos de conhecimento e habilidades é possível aos demais componentes e áreas da BNCC, mas é incompatível com a não existência dos conteúdos no componente Arte. Compreendemos que tal definição será imprescindível na avaliação das habilidades.

A avaliação em Arte sempre foi uma tarefa de difícil realização pelos professores, nos PCN havia indicações de expectativas de aprendizagem que os norteavam. Na BNCC, as habilidades e as competências serão avaliadas, contudo, isso não garante a avaliação qualitativa dos processos de criação dos alunos nas seis dimensões do conhecimento propostas no documento, isso demandará dos professores o exame de outros 
indicadores para observar tais aprendizagens.

Está prevista a formação docente para o uso do novo documento, contudo, como vimos, a BNCC de Arte é aberta e sem definição dos conteúdos e procedimentos didáticos no que se refere à parte comum exigida das escolas, o que pode redundar na reprodução dos paradigmas equivocados que, sabidamente, marcam nossos contextos educativos no componente Arte: a livre-expressão e a educação tradicional. A criatividade do professor para inventar propostas autorais e atualizadas em sala de aula ou selecionar o livro didático depende de formação teórica e prática de modo articulado, com domínio dos conteúdos do componente que ensina e dos procedimentos didáticos a eles adequados.

Cotejando aspectos dos dois documentos, verificamos que a proposta da BNCC de Arte do Ensino Fundamental I, enquanto documento que delineia e não apenas norteia a escrita curricular como foram os PCN, só cumprirá seus propósitos se as definições que foram delegadas às equipes vierem acompanhadas por políticas públicas de formação voltadas às linguagens específicas e à valorização dos docentes e da arte na Educação.

Um grande esforço terá que ser realizado pelas equipes das escolas e redes para se afinarem com as proposições da BNCC, porque o documento é um fato inexorável. A formação inicial, mesmo com estágios em sala de aula, colabora, mas não prepara os futuros professores para planejar e transformar continuamente o trabalho no dia a dia com os alunos. (IAVELBERG; SILVA, 2017). O enfrentamento das questões que emergem nas escolas, como a que está por vir com a implantação da BNCC, pede que se possa experimentar a desestruturação parcial de projetos em andamento para realizar reestruturações, levando em consideração as novas políticas públicas. No caso da BNCC, essas políticas são de Estado, mas com forte tendência partidária, haja vista a mudança de equipe de elaboradores no componente Arte das versões iniciais para a terceira versão, ocorrida com a mudança da presidência do país.

Acreditamos ser importante fortalecer a autonomia dos professores e gestores, porém se sabe que isto não depende apenas do esforço desses profissionais. Em nada resultará o documento da BNCC, mesmo que acompanhado de propostas de formação continuada, sem um cuidado permanente com a prioridade que deve ser dada à formação artística e cultural na educação das crianças e jovens, bem como às condições da formação inicial, da formação continuada e de trabalho dos professores.

Em relação às condições de trabalho do professor nos esclarece Saviani:

Ao encerrar esse trabalho não posso me furtar de chamar a atenção para o fato de que a questão da formação de professores não pode ser dissociada do problema das condições de trabalho que envolvem a carreira docente, em cujo âmbito devem ser equacionadas as questões do salário e da jornada de trabalho. Com efeito, as condições precárias de trabalho não apenas neutralizam a ação dos professores, mesmo que fossem bem formados. Tais condições dificultam também uma boa formação, pois operam como fator de desestímulo à procura pelos cursos de formação docente e à dedicação aos estudos (SAVIANI, 2009, p.153).

A diversidade curricular no país vai ocorrer a partir da BNCC e não poderia se dar de outra forma nos estados e municípios. É possível antever dificuldades na escrita curricular a ser realizada devido à incoerência interna no documento. Nele, as áreas e componentes deveriam dialogar, entretanto, a trama que os ordena é composta por: objeto de conhecimento, unidades temáticas, competências e habilidades que não conversam entre si nas ações interdisciplinares; ao contrário, na leitura da BNCC transparecem diferentes áreas, componentes $\mathrm{e}$ proposições justapostas. Apesar dos percalços que apontamos na BNCC, por um lado, constatamos que novas propostas se instalam nas descontinuidades, ou seja, quando o texto do documento inova ou abandona algumas proposições dos PCN. Por outro lado, nos deparamos com continuidades de aspectos postos nos PCN, quando a escrita conserva orientações ou cria derivações a partir das propostas já existentes na redação anterior.

Sendo assim, para além da compreensão de questões que emergiram da investigação realizada, é nas diferenças entre os documentos que poderia residir uma atualização em relação à realidade educacional contemporânea em nosso país, tendo em vista que 20 anos se passaram da escrita dos PCN de Arte à elaboração da terceira versão da BNCC. Observamos ainda, avanços na BNCC que se devem à alteração na lei da Educação Básica em 2010, portanto, que já vigorou, sem ter havido reformulação nos textos, na vigência dos $\mathrm{PCN}, 13$ anos depois de sua elaboração. Tais mudanças foram incluídas nas Diretrizes Curriculares Nacionais da Educação Básica (DCNEB), em 2013, e se referem ao ensino das produções artísticas que 
foram as matrizes da arte brasileira, expandindo o valor da arte regional.

A alteração na lei para a Educação Básica foi sancionada pelo presidente Luiz Inácio Lula de Silva em 2008, na gestão do ministro da Educação, Fernando Haddad, nos seguintes termos:

Art. 26

$\S 2^{\circ} \mathrm{O}$ ensino da arte, especialmente em suas expressões regionais, constituirá componente curricular obrigatório nos diversos níveis da educação básica, de forma a promover $\mathrm{o}$ desenvolvimento cultural dos alunos.

[...] (NR).

Art. $2^{\circ}$ Esta Lei entra em vigor na data de sua publicação.

Brasília, 13 de julho de 2010. (BRASIL, 2013, p. 31).

Apesar dos avanços, limites de ordem política e econômica se impuseram à terceira versão da BNCC e marcaram a escrita do documento, na medida em que, como se sabe, não existiu investimento para que a equipe de elaboradores da referida versão fosse oriunda das diferentes linguagens da Arte, como ocorreu nos PCN. Isso pode explicar a pouca diferenciação das habilidades entre as linguagens, a magra explicitação de conteúdos e, mais uma vez, nos alerta para o grande esforço a ser feito na formação dos professores de Arte, enquanto profissionais práticos reflexivos, com autonomia para a implantação da BNCC.

Muitos que abraçam o conceito de professor como prático reflexivo veem os professores como líderes que podem aprender com os outros e ali, por vezes, assumir o poder, mas que, no fim, não são subservientes relativamente aos que não estão na sala de aula. Segundo Dewey, as ações dos professores reflexivos são projetadas e planejadas de acordo com os fins que têm em vista, o que lhes permite saberem quem são e como agem (ZEICHNER, 1993, p.20).

Em conclusão, queremos ressaltar que um programa de implantação da BNCC, nos contextos escolares, está previsto a partir da quarta versão, na qual as redes de ensino terão que reconstruir tanto seus desenhos curriculares como os projetos político-pedagógicos, à época dos $\mathrm{PCN}$ a adesão a essas reformulações foi optativa. De qualquer forma, a escrita curricular é um projeto coletivo que precisa atender aos anseios de professores, gestores e da comunidade mais ampla, enquanto cidadãos participativos do tecido social. Em relação à cidadania nos diz Machado (1995, p. 47, grifos do autor):

De fato, associando-se as noções de cidadania e de projeto em sentido amplo, tal como anteriormente se delineou, nada parece mais característico da ideia de cidadania do que a construção de instrumentos legítimos de articulação entre projetos individuais e projetos coletivos. Tal articulação possibilitará aos indivíduos em suas ações ordinárias, em casa, no trabalho, ou onde quer que se encontrem, a participação ativa no tecido social, assumindo responsabilidades relativamente aos interesses e ao destino de toda a coletividade. Neste sentido, educar para a cidadania significa prover os indivíduos de instrumentos para a plena realização desta participação motivada e competente, desta simbiose entre interesses pessoais e sociais, desta disposição para sentir em si as dores do mundo.

$\mathrm{Na}$ sucessão dos censos escolares, ainda encontramos carência de professores com formação específica na linguagem que ensinam, muito embora esses números melhorem progressivamente, nos deparamos com a falta de profissionais licenciados e com o fato de que do $1 .^{\circ}$ ao $5 .^{\circ}$ ano, docentes com diploma de Pedagogia podem ministrar aulas de Arte no formato da polivalência, veementemente combatido, tanto pelas Associações Regionais, como pela Federação dos Arte-Educadores do Brasil.

Diante disso, na formação continuada dos professores, o conhecimento didático e o de Arte serão relevantes na implementação da $\mathrm{BNCC}$, isso não solucionará o conjunto de questões que as equipes escolares têm pela frente na reformulação do texto curricular e na reorientação das práticas em sala de aula. O grande desafio, entendemos, será trabalhar do $1 .^{\circ}$ ao $5 .^{\circ}$ ano, com as 26 habilidades a serem desenvolvidas e as 27 competências a serem promovidas no componente Arte. Para tanto, será preciso garantir que os profissionais da educação escolar em Arte sejam protagonistas de suas práticas e sabedores das teorias que abraçam. Infelizmente, ao contrário dos $\mathrm{PCN}$, a $\mathrm{BNCC}$ não oferece referências bibliográficas para que professores e gestores possam compreender e aprofundar suas proposições.

Em vista das análises aqui realizadas, consideramos condição fundamental que a didática 
da formação continuada dos professores de Arte na implantação da BNCC comungue dos mesmos princípios da que será levada às salas de aula, para que os docentes possam articular teoria e prática em diálogo com os fundamentos metodológicos que adotarão. Com isso, professores práticos reflexivos poderiam dialogar com as histórias e as culturas dos diferentes contextos educativos. Professores, assim formados e apoiados por seus gestores, definindo os conteúdos do ensino, talvez façam da BNCC um passo adiante, apesar de sua estrutura e de sua concepção por competências e habilidades - noções vindas do mundo do trabalho e, portanto, a serviço da lógica do capital. A redação dos currículos e dos projetos políticos pedagógicos que estão por vir, associada à formação dos professores, não corresponde a todas as necessidades de valorização do componente, contudo, talvez consiga impulsionar a melhoria da Arte na educação escolar.

\section{Referências}

BARBOSA, Ana Mae. A imagem no ensino da arte. 9 ed. São Paulo: Perspectiva, 2014.

BRASIL. Governo Federal. Base Nacional Comum Curricular: Fundamentos Pedagógicos e Estrutura Geral da BNCC: versão 3, Brasília, 2017a. Disponível em: <http://basenacionalcomum.mec.gov.br/images/BN CC_publicacao.pdf>. Acesso em: 12 set. 2017.

BRASIL. Lei No 12.287, de 13 de julho de 2010. Altera a Lei $\mathrm{n}^{\circ}$ 9.394, de 20 de dezembro de 1996, que estabelece as diretrizes e bases da educação nacional, no tocante ao ensino da arte. Diário Oficial da União, Seção 1, 14/7/2010, Página 1 (Publicação Original). Brasília, DF. Disponível em: <http://www2.camara.leg.br/legin/fed/lei/2010/lei12287-13-julho-2010-607263-publicacaooriginal128076-pl.html>. Acesso em: 23 nov. 2017.

BRASIL. Ministério da Educação. Fundo Nacional de Desenvolvimento. Secretaria de Educação Básica. Edital de convocação 01/2108 - CGPLI Edital de convocação para o processo de inscrição e avaliação de obras e práticas para o programa nacional do livro e do material didático (PNLD 2019), Brasília, 2017b. Disponível em: http://www.fnde.gov.br/programas/programas-dolivro/consultas/editais-programas-livro/item/10521- pnld-2019. Acesso em: 11 out. 2017.

BRASIL. Ministério da Educação. Secretaria de Educação Básica. Diretrizes Curriculares Nacionais da Educação Básica. Brasília: MEC/SEB/DICEI, 2013.

BRASIL. Ministério da Educação. Secretaria de Educação Fundamental. Parâmetros Curriculares Nacionais: Arte, Ensino de primeira à quarta série, Brasília: MEC/SEF, 1997.

CARVALHO, José Sergio Fonseca de. Educação uma herança sem testamento: diálogos com o pensamento de Hannah Arendt. 1 ed. São Paulo: Perspectiva, 2017.

FERRAZ, Heloísa C. de T.; FUSARI, Maria F. de Rezende e. Metodologia do ensino da arte. 2. ed. rev. ampl. São Paulo: Cortez, 2009.

IAVELBERG, Rosa; SILVA, Cintia Moreira da. O espaço da experiência no cotidiano escolar em tempos avessos à arte-educação. In: CORASSA, Maria Auxiliadora de Carvalho; GONÇALVES, Maria Gorete Dadalto; REBOUÇAS, Moema Martins (Orgs.). Sentidos e Significações de uma Educação em Artes Visuais em Tempos Contraditórios. Vitória: Ed. UFES, 2017. p. 21-31. Disponível em: <http://www.gepelufes.com/pg/28166/pesquisaseventos/>. Acesso: 10 jun. 2017.

MACHADO, Nilson José. Epistemologia $e$ didática: as concepções de conhecimento e inteligência e a prática docente. 1 ed. São Paulo: Cortez, 1995.

SAVIANI, Demerval. Formação de professores, aspectos históricos e teóricos no contexto brasileiro. Revista Brasileira de Educação. n. 40, p. 143-155 jan./abr. 2009.

ZABALA, Antoni. A prática educativa. 1 ed. Porto Alegre: Artmed, 1998.

ZABALA, Antoni; ARNAU, Laia. Como aprender e ensinar competências. 1 ed. Porto Alegre: Penso, 2010.

ZEICHNER, Kenneth. M. A formação reflexiva de professores: ideias e práticas. 1 ed. Lisboa: Educa, 1993. 


\section{Sobre a autora}

Rosa Iavelberg: Graduada em Arquitetura pela FAU USP (1973), mestre em Educação pela USP (1993) e doutora em Artes pela ECA USP (2000). Tem especialização em arte-educação I e II na ECA USP (1989). Atualmente é livre-docente e pesquisadora, atuando na graduação e pós-graduação da FE USP. Líder do Grupo de pesquisa Formação de Professores em Arte (CNPq) http://lattes.cnpq.br/3612410780790990.

Recebido em novembro de 2017.

Aprovado em março de 2018. 